\title{
Prognostic Value of Gated SPECT after Reperfusion for Acute Myocardial Infarction
}

\author{
Lázaro O. Cabrera-Rodríguez MD, Amalia T. Peix MD PhD DrSc, Kenia M. Padrón MD, Deilys Chacón MD, Regla Carrillo, \\ Yoel Fernández, Erick Mena
}

\begin{abstract}
INTRODUCTION Myocardial reperfusion during the course of an acute myocardial infarction improves patients' short- and long-term prognosis; coronary blood flow is successfully re-established while preserving a large amount of at-risk muscle. Clinical evolution, however, varies. Presence of residual ischemia or viable myocardial tissue affects a patient's prognosis. Assessment by noninvasive methods allows better prognostic stratification. Cardiac-gated SPECT provides appropriate parameters to support treatment selection and monitoring of these patients.
\end{abstract}

OBJECTIVES Assess the prognostic value-ability to predict occurrence of major cardiac events-of perfusion and cardiac function obtained by myocardial perfusion scintigraphy in myocardial infarction patients treated by any myocardial reperfusion method, whether pharmacological or surgical.

METHODS Forty patients were included, mean age $58.8 \pm 9$ years, diagnosed with myocardial infarction. Participants were divided into two groups: primary percutaneous transluminal coronary angioplasty (15) or thrombolysis (25). All received myocardial perfusion scintigraphy with cardiac-gated SPECT to assess perfusion and left ventricular function, and were followed for six months with telephone interviews and review of clinical records.

RESULTS In the 11 patients who had major cardiac events within six months of followup, a nonsignificant increase in perfusion defect extent was seen post reperfusion. Six $(54.5 \%)$ of those with major cardiac events had anterior perfusion defects. In functional parameters, a significant increase in end-diastolic and end-systolic volumes and decrease in left ventricular ejection fraction were observed post stress $(p=0.006)$ and at rest $(p=0.001)$. Post-stress end-diastolic volume of $\geq 70 \mathrm{~mL}$ had a higher prognostic value for major cardiac events [sensitivity $100 \%$; specificity $89 \%$, area under ROC curve $0.835(\mathrm{Cl}$ $0.702-0.969), p=0.001$ ]

CONCLUSIONS Cardiac-gated SPECT is useful to identify variables (including left ventricular systolic dysfunction and dilation of left cavities, particularly left end-systolic volume of $>70 \mathrm{~mL}$ ) predictive of major cardiac events in reperfused patients, independent of treatment modality.

KEYWORDS Scintigraphy, cardiac-gated SPECT, single-photon emission computer-assisted tomography, myocardial infarction, myocardial reperfusion, percutaneous transluminal coronary angioplasty, thrombolysis, prognosis, Cuba

\section{INTRODUCTION}

Current acute myocardial infarction (AMI) treatment has improved patients' short- and long-term prognoses. The main therapies work by treating thrombus formation and progression of platelet aggregation and by reducing ischemia, hence preserving cardiac muscle.[1] Early application of myocardial reperfusion techniques-initially thrombolytic drugs and later percutaneous transluminal coronary angioplasty (PTCA) - [2] increases the chances of success in re-establishing coronary circulation. Intracoronary drug-eluting stents and platelet antiaggregant therapy reduce complications and need for reintervention.[3]

Patient progress after reperfusion is not always satisfactory; in the first year, there can be complications such as angina recurrence, AMI, need for reintervention, or death from cardiac causes. Identification of which reperfused patients may suffer a more unfavorable evolution enables implementation of tailored treatment strategies. $[4,5]$

Myocardial perfusion scintography (MPS) permits prognostic stratification of AMI patients. Perfusion and myocardial function obtained by MPS help identify risk variables, enabling individualization of patient care and fewer future complications for reperfused patients.[6-9] Most studies to date have focused on results of myocardial perfusion and ejection fraction. However, we believe it is important to study additional data that can be obtained from gated MPS, in which acquisition is synchronized with the R wave of the electrocardiogram to obtain end-diastolic and end-systolic images. This enables calculation of ventricular function, including: ventricular volumes, behavior of ejection fraction, regional motil- ity and systolic thickening. These ventricular function variables complement information obtained about myocardial perfusion.

The combination of normal stress test results with normal images of myocardial perfusion and ventricular function (ejection fraction $>55 \%$ ) has an excellent prognosis, with a combined annual mortality rate from cardiac causes (fatal AMI and/or ventricular arrhythmia) and nonfatal myocardial infarction of $<1 \%$ and an annual mortality rate of $<0.2 \%$. $[10,11]$ This low fatality rate from cardiac events remains constant even when the stress test is positive for ischemia or in the presence of significant coronary stenosis in myocardial angiography.[12-15] Abnormal myocardial perfusion images, however, are associated with a $7 \%$ increase in risk of cardiac-related deaths during the first year of followup.[16]

This study's objectives were to determine the value of MPSspecifically, cardiac-gated SPECT (single-photon emission-computed tomography), known as gSPECT, in identifying prognostic perfusion and function variables in AMI patients treated by either myocardial reperfusion method, and to assess these variables' ability to predict occurrence of major cardiac events.

\section{METHODS}

Population An observational, longitudinal prospective study was conducted of first-time AMI patients admitted to emergency service of the Cardiology and Cardiovascular Surgery Institute (ICCC, the Spanish acronym) in Havana between January and July 2010. The study looked at the 40 patients treated with thrombolysis or primary PTCA who were referred to nuclear medicine services by their attending cardiologists for perfusion studies from 
30 to 45 days post AMI; patients were excluded if they had conditions that complicate perfusion study interpretation (complete left bundle branch block, cardiac arrhythmia) or other known cardiac diseases (valvulopathies; dilated, hypertrophic or restrictive myocardiopathy). Sociodemographic statistics such as sex and age were collected as well as clinical conditions including arterial hypertension, diabetes mellitus, smoking and blood lipid levels.

Two treatment groups were formed: group 1 included those who received primary PTCA and group 2 those who received thrombolysis. After reperfusion, a myocardial perfusion test was performed with physical or pharmaceutical stress between 30 and 45 days after the acute event.

Patients were followed up for six months during the myocardial perfusion study, through review of clinical records and/or telephone interview. We determined whether major cardiac events (nonfatal MI, admission for non-ST elevation acute coronary syndrome, or cardiac death) had occurred and created groups for analysis by presence or absence of these outcomes to identify predictive gSPECT variables.

gSPECT A two-day stress/rest protocol by gSPECT was performed on all myocardial-perfusion patients.[17] Physical stress was conducted on a treadmill (Schiller, Switzerland), beginning with an initial load of $25 \mathrm{~W}$ followed by successive 2-minute increments until reaching maximum cardiac frequency (CF, 220 minus patient age) or physical exhaustion, hypotension or ST segment depression of $>0.2 \mathrm{mV}$. Thirty to 60 seconds before completion of the effort, patients were injected with radiocontrast agent Tc-99m $\mathrm{MIBI}(20 \mathrm{mCi})$. The second day, resting images were taken using the same doses of the radiocontrast agent. Pharmacological stress with dipyridamole was used in patients who had limitations in physical exercise. Images were taken 45 minutes after injection, doing gated studies with the $\mathrm{R}$ wave of electrocardiogram, facilitating acquisition of end-diastolic and end-systolic images for calculating left ventricular function.

For gSPECT acquisition, images were taken using a dual-head gamma camera (Mediso, Hungary) with high-resolution collimator and parallel holes in an anterior orbit of $180^{\circ}$ (from right anterior oblique $45^{\circ}$ to left anterior oblique $45^{\circ}$ ) in step-and-shoot mode, with 20 seconds per projection for the radiocontrast; 32 projections were conducted with a $64 \times 64$ × 16-matrix and an energy emission window of $140 \pm 10 \% \mathrm{keV}$. The study was synchronized with ECG at eight frames per cycle in supine position. Filtered backprojection was used, obtaining short and long horizontal-axis cross sections and long vertical-axis cross sections; attenuation was not corrected.

Interpretation of perfusion images For semi-quantitative visual interpretation of images we used short- and long-axis vertical tomograms divided into 17 segments. Each segment was analyzed by two independent observers without clinical or angiographic information. A 5-point system was applied ( $0=$ normal capture, up to $4=$ absence of capture); summed scores were computed for stress and resting states and differences between the two. Disagreements in interpreting images were resolved by expert consensus. Capture was considered improved in the followup study if the score dropped by $\geq 1$ point in relation to the stress study. Emory software[18] was used for observers' independent analysis of ventricular function variables: regional wall motion, left ventricular ejection fraction (LVEF), end-diastolic volume (EDV) and end-systolic volume (ESV) of the left ventricle (LV).

Myocardial perfusion scintigraphy was reported as normal (absence of perfusion defects with normal LV regional and overall function), abnormal (definite anomaly in perfusion and/or anomaly of LV regional and/or overall function) or equivocal (images do not meet criteria for either of the two previous categories).

Normal studies were defined by normal myocardial perfusion upon visual analysis, normal wall movement, and normal systolic thickening. Severity of myocardial perfusion defects was recorded as a summed difference score, with a score of $\leq 3$ considered normal; 4 to 8 , slight ischemia; 9 to 12 , moderate ischemia; and $\geq 13$, severe ischemia.[19]

The following poor-prognosis variables were assessed: ischemia in area of anterior descending coronary artery, two or more coronary areas with perfusion defects, end-diastolic volume $>120 \mathrm{~mL}$ and end-systolic volume $>70 \mathrm{~mL}$, global resting LVEF $<40 \%$, poststress LVEF reduced by $\geq 5 \%$, transient ischemia dilation $<1.12$. [20-22].

Statistical analysis Distribution and correlation of general patient characteristics in the study were assessed. Categorical variables (including age, sex, arterial hypertension, diabetes mellitus, cholesterol and smoking) were expressed in absolute numbers and percentages, and continuous variables (ejection fraction; ventricular volumes; and post-stress, resting and summed difference scores) expressed in average values and standard deviations. The two groups were compared using the chi-square for categorical variables and the Student $t$ test for quantifiable variables. A probability of $<0.05$ was considered significant. To assess degree of association of variables with major cardiac events, the odds ratio was also calculated with a 95\% confidence interval. Also determined were sensitivity, specificity and area under the ROC curve of variables significantly associated with major cardiac events in univariate analysis. An area under the curve of 0.8 was specified as having optimal balance between sensitivity and specificity. SPSS 13.0 for Windows was used for statistical processing.

Ethics The study was approved by the Cardiology and Cardiovascular Surgery Institute ethics committee. Prior written informed consent was obtained from all participants.

\section{RESULTS}

Patient characteristics Of the 40 patients, 62.5\% (25/40) were treated with thrombolysis and $37.5 \%(15 / 40)$ with primary PTCA. Men accounted for $80 \%$ (32/40) of the sample; $40.6 \%(13 / 32)$ of men received primary PTCA, while only $25 \%(2 / 8)$ of women received such treatment.

Average age was $58.8 \pm 9$ years. There was no significant difference between the PTCA and thrombolysis groups in behavior of coronary risk factors: arterial hypertension, $66.7 \%$ (10/15) versus $56 \%(14 / 25)$ respectively; dyslipidemia, $46.7 \%$ (7/15) versus $32 \%$ (8/25); diabetes mellitus, $26.7 \%(4 / 15)$ versus $16 \%(4 / 25)$; and smoking, $73.3 \%(11 / 15)$ versus $76 \%(19 / 25)$.

Inferior myocardial infarction was the most common, $52.5 \%$ of total (21/40), followed by anterior in $37.5 \%$ (15/40). 
Initial assessment of myocardial perfusion and ventricular function Semiquantitative analysis of perfusion showed no significant differences between treatment groups post reperfusion: mean values of summed stress, resting, and difference scores were similar, independent of treatment modality (Table 1). Thrombolyzed patients showed greater resting and post-stress enddiastolic and end-systolic volumes and lower LVEF than PTCA patients, without reaching statistical significance. The groups were similar in respect to $a \geq 5 \%$ post-stress drop in FEV1 and transient left ventricular ischemic dilation (Table 1).

Table 1: Initial gSPECT findings by reperfusion modality

\begin{tabular}{|l|r|r|r|}
\hline Parameter & $\begin{array}{c}\text { PTCA } \\
\mathbf{n}=\mathbf{1 5}\end{array}$ & $\begin{array}{c}\text { Thrombolysis } \\
\mathbf{n = 2 5}\end{array}$ & $\begin{array}{c}\mathbf{P} \\
\text { Value }\end{array}$ \\
\hline SSS & $12.3 \pm 5.7$ & $13.2 \pm 6.7$ & 0.656 \\
\hline SRS & $7.6 \pm 5.8$ & $9.0 \pm 7.4$ & 0.498 \\
\hline SDS & $4.2 \pm 2.6$ & $4.1 \pm 3.3$ & 0.993 \\
\hline Post-stress LVEF $(\%)$ & $64.3 \pm 14$ & $56.8 \pm 12$ & 0.097 \\
\hline Resting LVEF $(\%)$ & $64.1 \pm 13$ & $58.1 \pm 12$ & 0.156 \\
\hline Post-stress drop in LVEF of $\geq 5 \%$ & $3(20.0 \%)$ & $6(24.0 \%)$ & 0.546 \\
\hline Post-stress EDV $(\mathrm{mL})$ & $95.5 \pm 44$ & $105.4 \pm 37$ & 0.477 \\
\hline Resting EDV $(\mathrm{mL})$ & $95.8 \pm 37$ & $102.8 \pm 28$ & 0.536 \\
\hline Post-stress ESV $(\mathrm{mL})$ & $36.6 \pm 37$ & $44.4 \pm 28$ & 0.497 \\
\hline Resting ESV $(\mathrm{mL})$ & $36.3 \pm 31$ & $42.4 \pm 21$ & 0.509 \\
\hline TID & $3(20.0 \%)$ & $3(12.0 \%)$ & 0.400 \\
\hline
\end{tabular}

EDV: end diastolic volume

ESV: end systolic volume

LVEF: left ventricular ejection fraction

PTCA: percutaneous transluminal coronary angioplasty

SSS: summed stress score

SRS: summed resting score

SDS: summed difference score

TID: transient ischemic dilation

Patient followup At six months of followup, 11 of the 40 patients had suffered major cardiac events, such as recurrence of angina, AMI, unstable angina and malignant ventricular arrhythmia. There was no statistically significant difference between thrombolyzed patients and the PTCA group: $36 \%(9 / 25)$ versus $14.3 \%(1 / 7$ patients) $(p=0.13$; OR 3.6, Cl 0.66-20.0).

At six months, patients who had had major cardiac events during followup were observed to have had a significantly lower initial LVEF, both in post-stress $(50.5 \%$ vs. $63.4 \%, p=0.006)$ and resting images $(50.3 \%$ versus $64.5 \%, p=0.001)$, compared to patients who remained asymptomatic (Figure 1). They also tended to have more areas with perfusion defects: $63.6 \%$ (7/11) had $\geq 3$ defects and only 1 had a single defect. Anterior perfusion defects were more common $(54.5 \%, 6 / 11)$ in patients who suffered acute cardiac events during followup.

Post-stress drops in LVEF of $\geq 5 \%$ were more common in patients with major cardiac events, although the difference was not significant ( $p=0.090$; OR 1.44, Cl 0.75-2.58).

Resting and post-stress end-diastolic and end-systolic volumes were significantly higher after reperfusion in patients who developed complications within six months of infarction. Poststress end-diastolic volume in patients with events averaged $136.3 \pm 51 \mathrm{~mL}$ versus $89.1 \pm 25 \mathrm{~mL}$ in those without events ( $p$ $<0.001$ ). Resting end-diastolic volume in patients with events averaged $119.6 \pm 35$ versus $93.2 \pm 27 \mathrm{~mL}$ in patients without ( $p=$ 0.038) (Figure 2). Post-stress end-systolic volume for patients with events averaged $68.2 \pm 45 \mathrm{~mL}$, versus $31.4 \pm 17 \mathrm{~mL}$ in those without events ( $p=0.000)$; and resting end-systolic volume averaged $59.2 \pm 33 \mathrm{~mL}$ in those with events versus $32.8 \pm 17 \mathrm{~mL}$ in those without $(p=0.002)$ (Figure 3$)$. Patients with major cardiac events showed wide variability in initial mean LVEF and end-systolic and end-diastolic ventricular volumes (resting as well as post stress).

The percentage of patients who presented post-stress transient ischemic dilation was three times higher for those with major cardiac events than for those who remained event-free: $37.5 \%$ versus $11.5 \%$, although the difference was not significant $(p=0.196$, OR 1.53, Cl 0.67-3.48).

A post-stress end-systolic volume of $\geq 70 \mathrm{~mL}$ was the gatedSPECT parameter with greatest predictive value for occurrence of major cardiac events within six months of followup, with a sensitivity of $100 \%$ and specificity of $86 \%$ (area under the ROC curve $0.835, \mathrm{Cl} 0.702-0.969, \mathrm{p}=0.001$; OR $1.54, \mathrm{Cl} 0.94-$ 2.55) (Figure 4). The remaining variables with significant correlation in univariate analysis showed an area under the ROC curve of $<0.80$.

\section{DISCUSSION}

This study corroborated the theory presented in Diego-Domínguez's review[23] of the prognostic value of changes in perfusion (localization and severity of ischemia as well as number of areas affected) as predictors of future coronary events. In addition, we observed that patients who experienced greater LVEF reductions and increased ventricular volumes (end-diastolic and endsystolic) at time of gSPECT suffered more coronary events in the six months following reperfusion than did patients without these responses.

Perfusion and myocardial function in relation to type of reperfusion PTCA patients had better clinical evolution with fewer coronary events than thrombolysis patients, although no significant differences were found in final necrosis extent. Gibbons studied a sample of 108 patients and found no differences in necrosis extent, independent of type of reperfusion,[24] which may be related to time elapsed between symptom onset and therapy initiation, a decisive factor in cardiac muscle rescue. Development of collateral circulation in the artery responsible for AMI ensures greater resolution of the ST segment with reduced necrotic area.[25]

Ndrepepa found that patients with revascularization by primary angioplasty and TIMI 3 flow (Thrombolysis in Myocardial Infarction grade three flow, in which the contrast opacifies the distal bed with the same intensity as the proximal in the coronary angiography study), but with insufficient myocardial perfusion, have poorer myocardial tissue rescue and hence a greater extent of necrosis. [26] In our study, angioplasty success was determined by TIMI 3 flow and not by tissue perfusion, a factor that explains why there are no differences in necrosis extent between the two groups.

Another factor explaining this phenomenon in our study is that the perfusion studies were conducted 30 to 45 days after the acute episode, when the phenomena of self-recovery in the chronic phase of AMI had already begun: spontaneous repermeabilization of the responsible artery and microcirculation and cellular function recovery.[27,28] 
Figure 1: Post-stress and resting left ventricular ejection fraction in relation to occurrence of major cardiac events after cardiac reperfusion
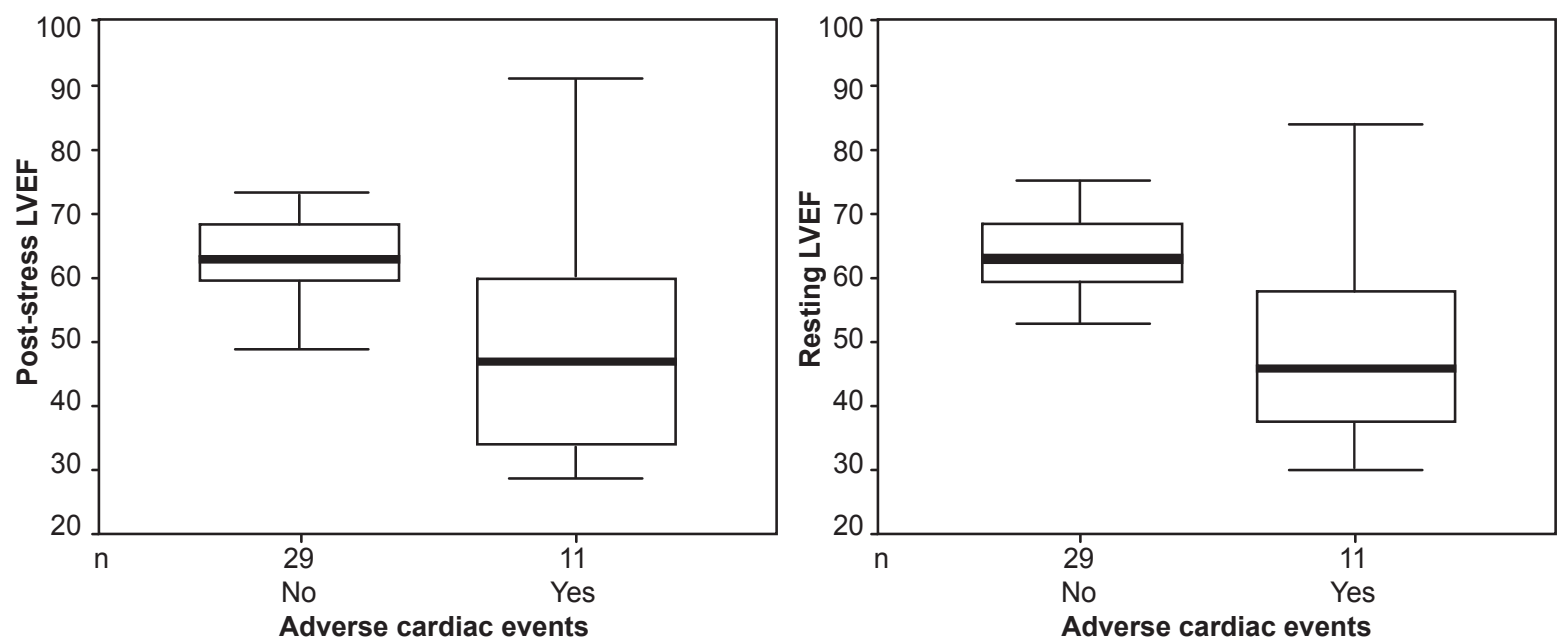

LVEF: left ventricular ejection fraction

Figure 2: Post-stress and resting end-diastolic volume in relation to occurrence of major cardiac events after cardiac reperfusion
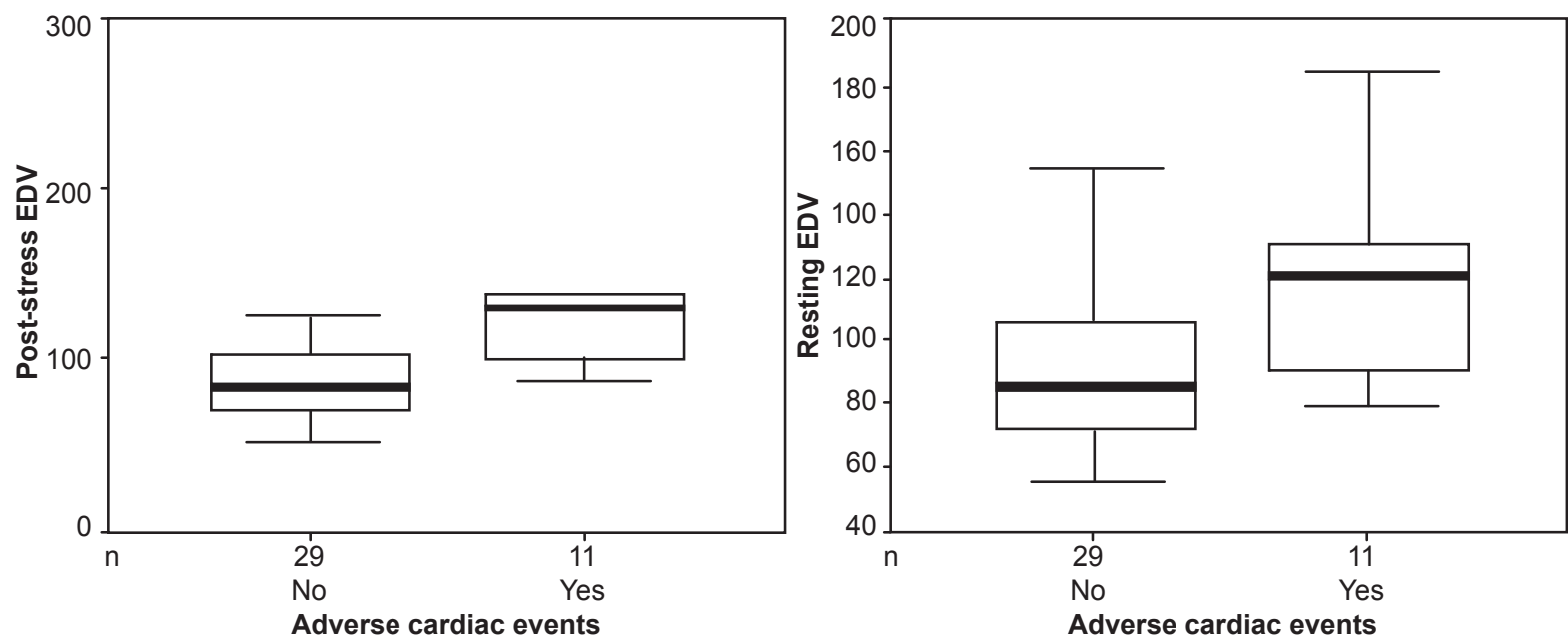

EDV: end-diastolic volume

Figure 3: Post-stress and resting end-systolic volume in relation to occurrence of major cardiac events after cardiac reperfusion
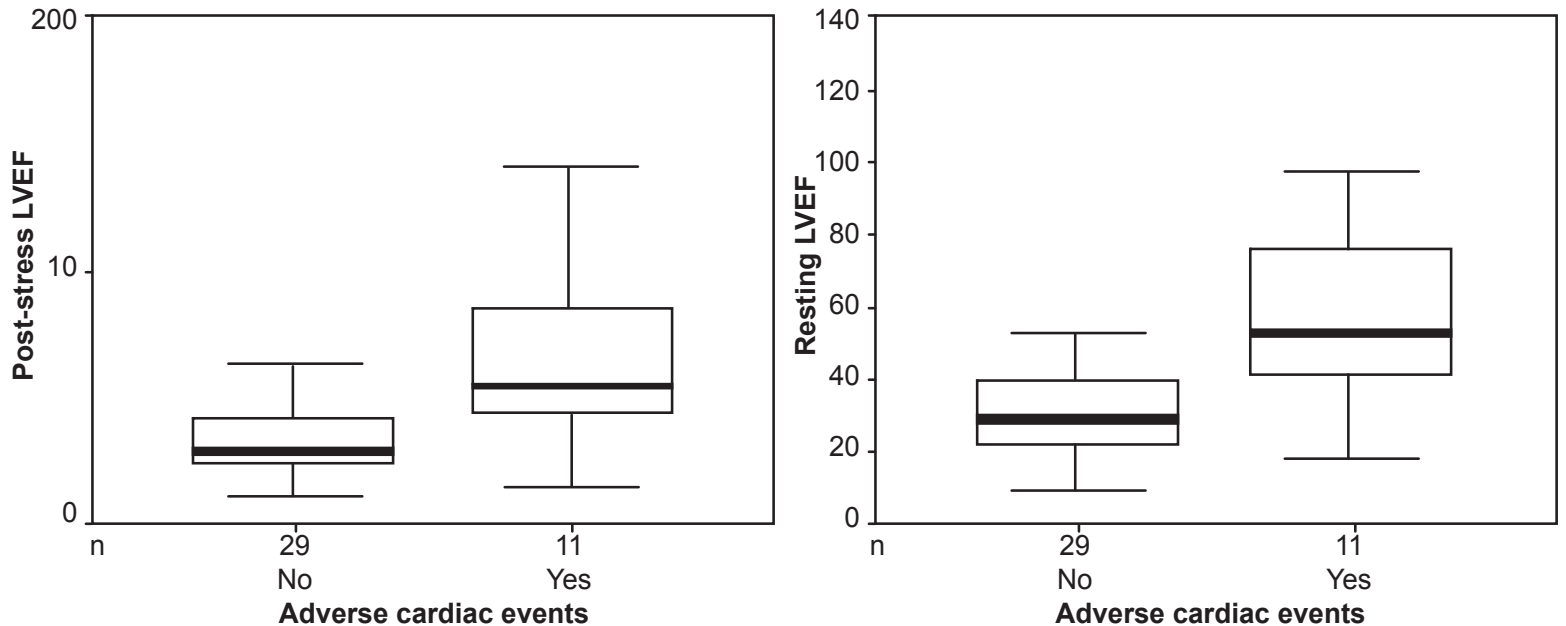

ESV: end systolic volume 
Figure 4: Post-stress end systolic volume related to major cardiac events after reperfusion (area under ROC curve)

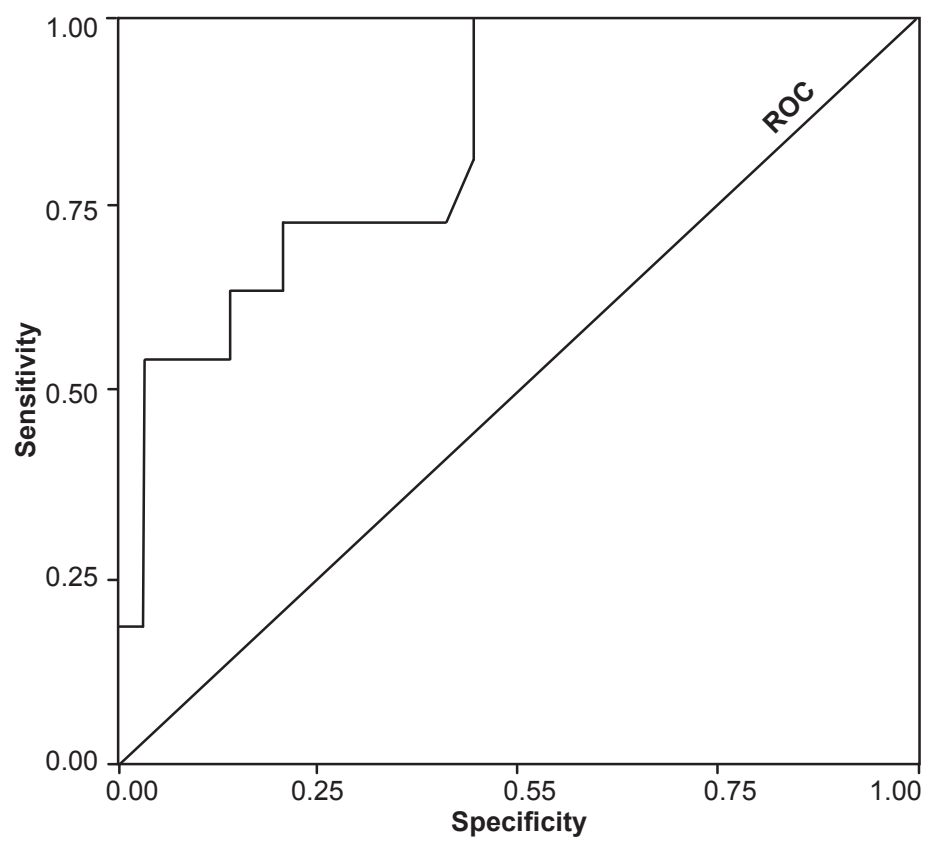

End-diastolic and end-systolic volumes were slightly lower in PTCA patients and LVEF was greater in this group, although these parameters were not statistically significant; this contrasts with Zachorski, who studied 40 AMI patients, finding LVEF significantly greater and end-systolic and end-diastolic volumes lower in PTCA than in thrombolysis patients.[29] These differences could be related to the fact that in their study, MPS was performed six months after revascularization, a period in which positive ventricular remodeling occurred, more markedly in PTCA patients.

Relation between occurrence of cardiac events and gSPECT parameters Disease in the anterior descending coronary artery correlates more closely with anterior perfusion defects (specificity $100 \%$ ) and these defects occupy close to $50 \%$ of left ventricular mass,[30] which explains the poorer prognosis for anterior AMI patients. This is congruent with our finding that more than half of patients with major cardiac episodes had anterior necrosis. Similar results are reported in earlier studies, such as Wong's in a 717-patient registry, which found a mortality rate of $78.6 \%$ when the anterior descending artery was responsible for the AMI.[27] Zeymer studied 1333 PTCA patients and found that involvement of the anterior descending artery in cardiogenic shock was an important predictor of in-hospital mortality.[31]

In our study we observed a tendency for major cardiac episodes to increase with increasing numbers of areas exhibiting perfusion defects; this did not reach statistical significance, but our sample was small. In contrast, Travin's study of 3207 patients found that more than one occurrence of perfusion defects in vascular areas led to an annual episode rate of $8.6 \%$, compared to $5.1 \%$ in the patients with only one vascular area affected ( $p=0.002)$; presence of several clinically important lesions in the coronary tree with coronary reperfusion generated a larger ischemic burden and increased probability of major cardiac episodes.[32] In Brown's series of 139 patients with thoracic pain and no prior MI, a logistic regression analysis revealed that number of ischemic segments was the only prognostic factor for death and/or MI in 3- to 5-year followup.[33]
Ventricular function analysis LVEF of $<40 \%$ was another functional parameter that correlated significantly with occurrence of major cardiac episodes. Similar results have been reported in the literature. Spinelli, in a study of 1680 patients with infarction who underwent PTCA or surgical revascularization, reported that the functional parameters LVEF and end-systolic and end-diastolic volumes correlated significantly with cardiac episodes.[34]

No important reductions in LVEF post stress were observed in the group of patients with major cardiac events, and there is no consensus yet on this factor's prognostic value. It has been observed that LVEF may barely drop in patients with significant inducible ischemia and that patients with normal myocardial perfusion studies can show significant LVEF reduction post stress, leaving in question whether the finding is a coincidence or really a sign of myocardial stunning from significant coronary disease. [35] However, in a study of 57 patients, Dona found a close correlation between a $>5 \%$ drop in LVEF and occurrence of acute cardiac episodes, independent of ischemia.[36] Given these contradictory results, we consider that the acquisition protocol can influence findings, since delay in taking post-stress images can allow time for recovery from ischemia-induced myocardial stunning.

A tendency was observed to both greater end-diastolic and endsystolic ventricular volumes in thrombolysis patients, related to the presence of cardiac events. Factors such as microcirculation dysfunction, myocytic death and changes in left ventricular structure can impede functional recovery and cause negative ventricular remodeling post infarction.[11]

In our study, end-systolic volume showed greater prognostic value than LVEF and was the most accurate hemodynamic predictor of mortality in AMI patients. In a study of 1680 patients, Sharir found that end-systolic volume and LVEF had greater prognostic value than information obtained only from perfusion,[22] consistent with our results. The prognostic superiority of end-systolic volume with respect to other functional parameters in our study may be because these patients experience negative ventricular remodeling with loss of the heart's ellipsoidal geometry and ventricular synchronism, leading to deterioration of left ventricular systolic function.

It is important to bear in mind that in prognostic stratification of patients for secondary prevention of AMI, nuclear medicine techniques can provide relevant information, not only about perfusion but also about functional variables useful for predicting future events and informing treatment selection.

Limitations The sample in this study was too small to permit creation of management guidelines for myocardial patients. Further studies are needed controlling for other variables related to the myocardial revascularization process, such as time between pain onset and reperfusion, whether through thrombolysis or PTCA, to avoid biased comparison of the effectiveness of the two procedures.

\section{CONCLUSIONS}

Several parameters identified by gSPECT were associated, independent of modality, with greater probability of major cardiac events in the first six months of followup after reperfusion post AMI. This finding supports gSPECT's usefulness in risk stratification for improved clinical management of such patients. -1 - 


\section{REFERENCES}

1. Hendel RC, Berman DS, Di Carli MF, Heidenreich PA, Henkin RE, Pellikka PA, et al. ACCF/ ASNC/ACR/AHA/ASE/SCCT/SCMR/SNM 2009 Appropriate Use Criteria for Cardiac Radionuclide Imaging: A Report of the American College of Cardiology Foundation Appropriate Use Criteria Task Force, the American Society of Nuclear Cardiology, the American College of Radiology, the American Heart Association, the American Society of Echocardiography, the Society of Cardiovascular Computed Tomography, the Society for Cardiovascular Magnetic Resonance, and the Society of Nuclear Medicine Endorsed. J Am Coll Cardiol. 2009 Jun 9;53(23):2201-29.

2. Barrabés JA, Sanchís J, Sánchez PL, Bardají A Actualización en cardiopatía isquémica. Rev Esp Cardiol. 2009;62(Suppl 1):80-91. Spanish.

3. Moreno R. Tratamiento de la angina estable: revascularización miocárdica. Rev Esp Cardiol. 2010;10(Suppl B):31B-40B. Spanish.

4. Wita K, Filipecki A, Szydło K, Turski M, Tabor Z, Wróbel W, et al. Prediction of long-term outcome after primary percutaneous coronary intervention for acute anterior myocardial infarction. Kardiol Pol. 2010 Apr;68(4):393-400.

5. Hachamovitch R, Hayes SW, Friedman JD, Cohen I, Berman DS. Comparison of the shortterm survival benefit associated with revascularization compared with medical therapy in patients with no prior coronary artery disease undergoing stress myocardial perfusion single photon emission computed tomography. Circulation. 2003 Jun 17;107(23):2900-7.

6. Casáns I, Jurado JA. Diagnóstico de la enfermedad coronaria mediante Gated-SPECT de perfusión miocárdica. Rev Esp Cardiol Supl. 2008;8(Suppl B):15B-24B. Spanish.

7. Beller GA, Zaret BL. Contributions of nuclear cardiology to diagnosis and prognosis of patients with coronary artery disease. Circulation. 2000 Mar 28;101(12):1465-78.

8. Evangelista L, Acampa W, Petretta M, Ferro A, Ricci F, Luongo L, et al. Incremental prognostic value of cardiac single-photon emission computed tomography after nitrate administration in patients with ischemic left ventricular dysfunction. J Nucl Cardiol. 2009 Jan-Feb;16(1):38-44.

9. Paul AK, Nabi HA. Gated myocardial perfusion SPECT: basic principles, technical aspects and clinical applications. J Nucl Med Technol. 2004 Dec;32(4):179-87.

10. Gibbons RJ. Noninvasive diagnosis and prognosis assessment in chronic coronary artery disease. Stress Testing with and without imaging perspective. Circ Cardiovasc Imaging. 2008 Nov;1(3):257-69.

11. Borges-Neto $\mathrm{S}$, Shaw LK, Tuttle RH, Alexander $\mathrm{JH}$, Smith WT 4th, Chambless M, et al. Incremental prognostic power of single-photon emission computed tomographic myocardial perfusion imaging in patients with known or suspected coronary artery disease. Am J Cardiol. $2005 \mathrm{Jan}$ 15;95(2):182-8.

12. Klodas E, Miller TD, Christian TF, Hodge DO, Gibbons RJ. Prognostic significance of ischemic electrocardiographic changes during vasodilatador stress testing in patients with normal SPECT images. J Nucl Cardiol. 2003 Jan-Feb;10(1):4-8.

13. Abbot BG, Afshar M, Berger AK, Wackers FJ. Prognostic significance of ischemic electrocardiographic changes during adenosine infusion in patients with normal myocardial perfusion imaging. J Nucl Cardiol. 2003 Jan-Feb;10(1):9-16.

14. Hachamovitch R, Hayes S, Friedman JD, Cohen I, Shaw LJ, Germano G, et al. Determinants of risk and its temporal variation in patients with normal stress myocardial perfusion scans. J Am Coll Cardiol. 2003 Apr 16;41(8):1329-40.

15. Elhendy A, Schinkel AF, van Domburg RT, Bax JJ, Valkema R, Huurman A, et al. Prognostic value of exercise stress technetium-99m-tetrofosmin myocardial perfusion imaging in patients with normal baseline electrocardiograms. J Am Coll Cardiol. 2006 Sep 1;98(5):585-90

16. Metz LD, Beattie M, Hom R, Redberg RF, Grady $D$, Fleichsman KE. The prognostic value of normal exercise myocardial perfusion imaging and exercise echocardiography: a meta-analysis. J Am Coll Cardiol. 2007 Jan 16:49(2):227-37.

17. Berman DS, Kiat HS, Van Train KF, Germano G, Maddahi J, Friedman JD. Myocardial perfusion imaging with technetium-99m-sestamibi: comparative analysis of available imaging protocols. $J$ Nucl Med. 1994 Apr;35(4):681-8.

18. Garcia EV, Faber TL, Cooke CD, Folks RD, Chen $\mathrm{J}$, Santana $\mathrm{C}$. The increasing role of quantification in clinical nuclear cardiology: the Emory approach. J Nucl Cardiol. 2007 Jul;14(4):420-32.

19. Hachamovitch R, Berman DS, Shaw LJ, Kiat $H$ Cohen I, Cabico JA, et al. Incremental prognostic value of myocardial perfusion single photon emission computed tomography for the prediction of cardiac death: differential stratification for risk of cardiac death and myocardial infarction. Circulation. 1998 Feb 17;97(6):535-43.

20. Weiss AT, Berman DS, Lew AS, Nielsen J, Potkin B, Swan HJ, et al. Transient ischemic dilation of the left ventricle on stress thallium-201 scintigraphy: a marker of severe and extensive coronary artery disease. J Am Coll Cardiol. 1987 Apr;9(4):752-9.

21. Candell J, Pereztol O, Oller G, Llevadot J, Aguadé $\mathrm{S}$, Castell J, et al. [Evolution of systolic function and myocardial perfusion, evaluated by gatedSPECT, in the first year after acute myocardial infarction]. Rev Esp Cardiol. 2003 May;56(5):43844. Spanish.

22. Sharir T, Germano G, Kavanagh PB, Lai S, Cohen I, Lewin HC, et al. Incremental prognostic value of post-stress left ventricular ejection fraction and volume by gated myocardial perfusion single photon emission computed tomography. Circulation. 1999 Sep 7;100(10):1035-42.

23. Domínguez MD, Muxí-Pradas MA. Pronóstico de la enfermedad coronaria crónica mediante gatedSPECT de perfusión miocárdica. Rev Esp Cardio Suppl. 2008;8(Suppl B):25B-34B. Spanish.

24. Gibbons RJ, Holmes DR, Reeder GS, Bailey KR, Hopfenspirger MR, Gersh BJ. Immediate angiolplasty compared with the administration of a thrombolytic agent followed by conservative treatment for myocardial infarction. The Mayo Coronary Care Unit and Catheterization Laboratory Groups. N Engl J Med. 1993 Mar 11;328(10):68591.

25. Sorajja P, Gersh BJ, Mehran R, Lansky AJ, Krucoff MW, Webb J, et al. Impact of collateral flow on myocardial reperfusion and infarct size in patients undergoing primary angioplasty for acute myocardial infarction. Am Heart J. 2007 Aug;154(2):37984.

26. Ndrepepa G, Mehilli J, Tiroch K, Fusaro M, Kufne $\mathrm{S}$, Ellert J, et al. Myocardial perfusion grade, myocardial salvage indices and long-term mortality in patients with acute myocardial infarction and ful restoration of epicardial blood flow after primary percutaneous coronary intervention. Rev Esp Cardiol. 2010 Jul;63(7):770-8. English, Spanish.

27. Wong SC, Sanborn T, Sleeper LA, Webb JG, Pilchik R, Hart D, et al. Angiographic findings and clinical correlates in patients with cardiogenic shock complicating acute myocardial infarction: a report from the SHOCK Trial Registry. Should we emergently revascularize occluded coronaries for cardiogenic shock? J Am Coll Cardiol. 2000 Sep;36(3 Suppl A):1077-83.

28. Elsman P, van 't Hof AW, Hoorntje JC, de Boer MJ, Borm GF, Suryapranata H, et al. Effect of coronary occlusion site on angiographic and clinical outcome in acute myocardial infarction patients treated with early coronary intervention. Am J Cardiol. 2006 Apr 15;97(8):1137-41.

29. Zachorski M, Dziuk M, Pietrzykowski J, Rdzanek $\mathrm{H}$, Kamiński G, Cholewa M, et al. [Left ven- tricular function in gated single photon emission computed tomography (GSPET) in patients with myocardial infarction subjected to thrombolysis or primary PTCA]. Pol Merkur Lekarski. 2005 Apr;18(106):376-9. Polish.

30. Pereztol O, Candell J, Santana C, Angel J, Aguadé $\mathrm{S}$, Castell J, et al. Correspondence between left ventricular 17 myocardial segments and coronary arteries. Eur Heart J. 2005 Dec;26(24):2637-43.

31. Zeymer U, Vogt A, Zahn R, Weber MA, Tebbe U Gottwik M, et al. Predictors of in-hospital mortality in 1333 patients with acute myocardial infarction complicated by cardiogenic shock treated with primary percutaneous coronary intervention ( $\mathrm{PCl})$; Results of the primary $\mathrm{PCl}$ registry of the Arbeitsgemeinschaft Leitende Kardiologische Krankenhausärzte (ALKK). Eur Heart J. 2004 Feb;25(4):322-8.

32. Travin MI, Heller GV, Johnson LL, Katten D, Ahlberg AW, Isasi CR, et al. The prognostic value of ECG-gated SPECT imaging in patients undergoing stress Tc-99m sestamibi myocardial perfusion imaging. J Nucl Cardiol. 2004 MayJun;11(3):253-62.

33. Brown KA, Boucher CA, Okada RD, Guiney TE, Newell JB, Strauss HW, et al. Prognostic value of exercise thallium-201 imaging in patients presenting for evaluation of chest pain. J Am Coll Cardiol. 1983 Apr;1(4):994-1001.

34. Spinelli L, Petretta M, Acampa W, He W, Petretta A, Bonaduce D, et al. Prognostic value of combined assessment of regional left ventricular function and myocardial perfusion by dobutamine and rest gated SPECT in patients with uncomplicated acute myocardial infarction. J Nucl Med. 2003 Jul;44(7):1023-9.

35. Ramakrishna G, Miller TD, Hodge DO, O'Connor MK, Gibbons RJ. Differences in left ventricular ejection fraction and volumes measured at rest and poststress by gated sestamibi SPECT. J Nucl Cardiol. 2006 Sep;13(5):668-74.

36. Dona M, Massi L, Settimo L, Bartolili M, Gianni G, Pupi A, et al. Prognostic implications of poststress ejection fraction decrease detected by gated SPECT in the absence of stress-induced perfusion abnormalities. Eur J Nucl Med Mol Imaging. 2011 Mar;38(3):485-90

\section{THE AUTHORS}

Lázaro O. Cabrera-Rodríguez (Corresponding author: cardiomar@infomed.sld.cu), cardiologist, nuclear medicine department, Cardiology and Cardiovascular Surgery Institute, Havana, Cuba.

Amalia T. Peix, cardiologist, Cardiology and Cardiovascular Surgery Institute (ICCC), Havana, Cuba.

Kenia M. Padrón, cardiologist, Nuclear medicine department, ICCC, Havana, Cuba.

Deilys Chacón Montano, cardiologist, Luis Díaz Soto Hospital, Havana, Cuba.

Regla Carrillo, nuclear medicine technician, nuclear medicine department, ICCC, Havana, Cuba.

Yoel Fernández, health technologist, ICCC, Havana, Cuba.

Erick Mena, health technologist, ICCC, Havana, Cuba.

Submitted: May 21, 2012

Approved for publication: April 21, 2013

Disclosures: None 